https://doi.org/10.14295/revistadaesmesc.v28i34.p298

\title{
ALIENAÇÃO PARENTAL: PRINCIPAIS ASPECTOS NO ÂMBITO FAMILIAR
}

\section{PARENTAL ALIENATION: MAIN ASPECTS OF THE FAMILY}

\section{Nathália Carneiro Neves ${ }^{1}$}

Resumo: A alienação parental é um instituto jurídico do Direito de Família que surgiu para identificar situações de abusos que ocorrem no âmbito familiar. Em razão dela, é possível reconhecer quando a criança está sofrendo abusos emocionais e até físicos por parte da pessoa que possui a guarda. A Lei que trata sobre o assunto foi inserida para auxiliar o magistrado na aplicação de sanções e para reconhecer o alienador. Será apresentado no artigo o conceito de alienação parental, seguido pelas características, os tipos de guarda mais usuais, bem como a denunciação caluniosa e as implantações de falsas memórias.

Palavras-chave: Alienação parental. Alienador. Guarda.

Abstract:Parental alienation is a legal institute of Family Law that emerged to identify situations of abuse that occur within the family, because of it is possible to recognize when the child is suffering emotional and even physical abuse by the person who has custody. The Law dealing with the matter was inserted to assist the magistrate in applying sanctions and to recognize the alienator. The concept of parental alienation will be presented in the article, followed by the characteristics, the most usual types of guards, as well as the slanderous denunciation and the implantation of false memories.

Keywords: Parental alienation. Alienator. Guard.

1. Bacharela em Direito pela Universidade do Sul de Santa Catarina (UNISUL). Formada no Módulo II da Escola Superior da Magistratura (ESMESC). Pós-graduanda em Direito Aplicado pela ESMESC. Residente Judicial. E-mail: nathalia.cneves@hotmail.com 


\section{INTRODUÇÃO}

As leis existem para amparar os conflitos resultantes do convívio em sociedade e devem estar em constante mudança para a efetiva entrega da tutela jurisdicional. Nesse sentido, as questões jurídicas do âmbito do Direito de Família causam mudanças no âmbito social, de maneira a contemplar soluções jurídicas urgentes, com a finalidade de resguardar direitos.

Como será analisado neste artigo, com o surgimento da alienação parental no âmbito familiar, surgiram mudanças e decisões jurídicas para melhor atender aos interesses familiares, como também aos interesses das crianças e dos adolescentes vítimas desse abuso moral.

\section{ALIENAÇÃO PARENTAL}

A alienação parental é resultante dos atos que afetam a saúde e a segurança dos envolvidos na relação afetiva. Por esse motivo, deixou de ser apenas um fator social de modo a integrar o âmbito jurídico. É oportuna, assim, a edição de normas tendentes à solução e ao tratamento dessa prática. Os prejudicados são as crianças e os adolescentes alienados, que têm o desenvolvimento sadio interrompido em razão da disputa de poder entre o guardião e a pessoa que não detém a guarda (WAQUIM, 2018, p. 68).

Esse artigo apresentará os principais tópicos a respeito da alienação parental, compreendida no âmbito do Direito de Família, além de aspectos que tratam sobre a guarda e suas modalidades.

\subsection{Conceito}

Considera-se como alienação parental a intervenção psicológica em que o alienador, que pode ser os avós, os pais ou outra pessoa que esteja sob vigilância da criança ou que possua sua guarda, promove a rejeição de um dos parentes próximos. $\mathrm{O}$ alienador manipula o filho e também se coloca como vítima para excluir o vínculo de afeto com o outro genitor, de forma a fazer com que a criança ou o adolescente acredite que 
um dos pais age de maneira bondosa e o outro, todavia, possui apenas características maldosas (ROSA, 2018, p. 454).

Na opinião de Carvalho (2018, p. 524), a alienação parental surge quando o filho rompe o vínculo de afeto, no sentido de afastar-se ou distanciar-se dos parentes próximos, seja dos avós, do pai, da mãe, ou de ambos e, por conseguinte, causa prejuízos ao menor (sic) pela falta da orientação paterna ou materna.

A causa da alienação parental ocorre, de forma muito comum, no período em que os genitores litigam e esquecem da importância relacionada às questões parentais, haja vista que, algumas vezes, a relação que está desgastada pode ocasionar a alienação parental. O fato é que esta pode ser praticada por qualquer dos genitores, de maneira a influenciar, de forma maléfica, o menor ( $\mathrm{sic}$ ) para rejeitar o outro genitor (MOREIRA, 2015, p. 55). Ademais, o alienador pode ter plena ciência de seus atos ou até agir de maneira que não saiba que está sendo caracterizada a alienação parental.

Leciona Ramos (2016, p. 148) que o alienador pratica a alienação no intuito de prejudicar a relação do menor (sic) com os familiares. Por isso, o principal objetivo com a alienação parental é que a criança ou o adolescente abandone um dos genitores. Além desse fator, os atos de alienação parental afetam o direito fundamental que a criança tem de convivência familiar, caracterizador de abuso moral, na medida em que a pessoa que detém a guarda forja no menor de idade sentimento de rejeição daquele que não possui a guarda, além de dificultar a relação entre ambos e o exercício da autoridade de um dos pais (LÔBO, 2017, p. 198).

Nesse mesmo sentido, o art. $3^{\circ}$ da Lei ${ }^{\circ} 12.318$, de 26 de agosto de 2010, que trata sobre a alienação parental, considera que a prática dos atos de alienação parental infringe direitos fundamentais da criança e do adolescente, constitui abuso moral e importa em descumprimento dos deveres inerentes à autoridade parental, ou decorrentes da tutela ou guarda. Dessa forma, permite-se a aplicação de medidas para inibir os efeitos da prática de alienação parental, desde a advertência ao aliena- 
dor até a suspensão da autoridade parental, de acordo com a verificação de cada hipótese concreta (CARVALHO, 2019, p. 536).

$\mathrm{O}$ art. $2^{\circ}$ da Lei $\mathrm{n}^{\mathrm{o}}$ 12.318/10 conceitua:

Art. $2^{\circ}$ Considera-se ato de alienação parental a interferência na formação psicológica da criança ou do adolescente promovida ou induzida por um dos genitores, pelos avós ou pelos que tenham a criança ou adolescente sob a sua autoridade, guarda ou vigilância para que repudie genitor ou que cause prejuízo ao estabelecimento ou à manutenção de vínculos com este. (BRASIL, 2010).

Oportuno destacar, a partir da verificação do dispositivo legal anteriormente referido, que a interferência mencionada diz respeito aos atos nefastos praticados pelo alienador, que geram sentimento de desafeto e abalam a relação entre filho e pai ou mãe. Ressalta-se que a caracterização da alienação parental se dará quando o relato que desqualifica o genitor for acompanhado de fatos que não são verdadeiros, sendo que tem o intuito de criar uma imagem desagradável e fazer com que o menor (sic) tenha sentimentos de repulsa pelo alienado (PEREIRA, 2019, p. 141).

Nessa esteira, a ruptura de um relacionamento pode causar sentimentos de repulsa ou vingança no parceiro, que "caso os filhos fiquem em sua companhia, ao ver o interesse do genitor em preservar a convivência com eles, tudo faz para separá-los" (DIAS, 2010). Nesse momento, inicia-se o discurso contra o genitor, no sentido de desmoralizá-lo e rejeitá-lo, ao passo que, com o tempo, a criança aceita como verdade o que lhe é verbalizado. Dessa maneira, a criança ou o adolescente cria laços com o genitor guardião e torna-se órfão do alienado (DIAS, 2010). Assim, consoante se infere da verificação desses autores citados, o conceito de alienação parental está relacionado com o fato do poder que o guardião possui sobre o filho.

Além disso, a separação conjugal possui ampla repercussão nos adolescentes e nos adultos, como, por exemplo, causa rebeldia, tristeza, depressão, desobediência e sensação de abandono. No caso de a separação ser acompanhada por sofrimento decorrente de conflitos, poderá culminar em atos de alienação parental, em que o alienador tenta 
estimular a separação entre o Menor (sic) e a pessoa que não possui a guarda (OLIVEIRA, 2015, p. 09; ROCHA, 2015, p. 88). Por sua vez, consoante se verifica a partir dos autores citados, a alienação parental decorre, na maioria das vezes, da separação conflituosa, uma vez que os ânimos estão mais acirrados, e as partes têm mais oportunidades de promover campanhas de desqualificação contra o outro, embora também pode ser iniciada após a separação amigável, durante a união estável ou casamento.

Explica Ullmann (2015, p. 101) que os atos de alienação parental podem ocorrer além do ambiente familiar, de forma que se incluem como cúmplices, conscientes ou não de suas ações, como, por exemplo, os amigos próximos, a escola e o psicólogo. Na escola, a controvérsia pode se iniciar com o contrato assinado por um genitor, uma vez que apenas aquele recebe informações sobre o filho e pode fazer com que o outro não obtenha informações sobre o menor de idade. Isso, por conseguinte, pode causar o afastamento entre ambos. Além do psicólogo, que, ao ajudar o alienador, influência a criança a se afastar do outro genitor, de forma que, assim, exerce os atos de alienação parental.

De acordo com Apostolo (2015, p. 20):

Na esfera jurídica, a Alienação Parental é entendida como uma forma de abuso emocional, pelo intenso dano causado ao psiquismo da criança. É comparada em termos de gravidade e malefícios emocionais ao abuso sexual. Visando coibir essa prática algumas medidas judiciais podem ser propostas, dentre elas: o tratamento psicológico, psicoterapia familiar, e nos casos cuja gravidade é extrema, é possível que seja determinada reversão da guarda em favor do genitor alienado.

Desse modo, evidencia-se que a alienação parental é caracterizada pelo distanciamento da criança em relação ao alienado em virtude dos relatos e das ações praticadas pelo alienador para desmoralizá-lo, que causam prejuízos emocionais aos envolvidos. 


\subsection{Características}

As características e o comportamento do alienador são de difícil reconhecimento. Nesse sentido, leciona Perez (2013, p. 48) que o rol exemplificativo da Lei $n^{\circ} 12.318 / 10$ tem por finalidade auxiliar o aplicador da lei a reconhecer indícios de alienação parental, além das hipóteses que representam as condutas clássicas do alienador.

Como descrito por Pereira (2013, p. 37), a alienação parental causa consequências graves e "tal perversidade não pode passar despercebida pelos operadores de Direito, que ao detectarem os elementos indicadores da alienação parental, devem buscar, inclusive na interdisciplinaridade, reportar a violência sofrida pelos filhos".

Consoante já demonstrado, é de difícil identificação o comportamento do alienador. Posto isso, o legislador tratou de indicar formas de alienação parental, que são identificadas pelo Juiz ou verificadas na perícia, praticadas diretamente pelo guardião do menor de idade ou com a assistência de terceiros, na forma do art. $2^{\circ}$, parágrafo único, da Lei $\mathrm{n}^{\mathrm{o}}$ 12.318/10 (PEREIRA, 2019):

Art. $2^{\circ}$ Considera-se ato de alienação parental a interferência na formação psicológica da criança ou do adolescente promovida ou induzida por um dos genitores, pelos avós ou pelos que tenham a criança ou adolescente sob a sua autoridade, guarda ou vigilância para que repudie genitor ou que cause prejuízo ao estabelecimento ou à manutenção de vínculos com este.

Parágrafo único. São formas exemplificativas de alienação parental, além dos atos assim declarados pelo juiz ou constatados por perícia, praticados diretamente ou com auxílio de terceiros:

I - realizar campanha de desqualificação da conduta do genitor no exercício da paternidade ou maternidade;

II - dificultar o exercício da autoridade parental;

III - dificultar contato de criança ou adolescente com genitor;

IV - dificultar o exercício do direito regulamentado de convivência familiar;

$\mathrm{V}$ - omitir deliberadamente a genitor informações pessoais relevantes sobre a criança ou adolescente, inclusive escolares, médicas e alterações de endereço; 
VI - apresentar falsa denúncia contra genitor, contra familiares deste ou contra avós, para obstar ou dificultar a convivência deles com a criança ou adolescente;

VII - mudar o domicílio para local distante, sem justificativa, visando a dificultar a convivência da criança ou adolescente com o outro genitor, com familiares deste ou com avós. (BRASIL, 2010).

$\mathrm{O}$ inciso primeiro diz respeito à atuação de um dos genitores que busca desqualificar o genitor alienado, quando no exercício da paternidade ou da maternidade, para promover a falsa impressão de que as ações daquele genitor estão equivocadas, o que causa o afastamento do filho em relação a um dos pais. No que tange ao inciso segundo, é caracterizado pela desautorização realizada pelo alienador quanto aos comandos do outro genitor a criança ou adolescente, de modo que lhe retira a autoridade em relação ao filho (FIGUEIREDO; ALEXANDRIDIS, 2014, p. 55).

Na visão de Pereira (2019, p. 140), o inciso primeiro compreende a desqualificação realizada pelo alienador contra o alienado, por meio de relatos que não são verdadeiros, e que tem por objetivo afastar a criança daquele que não tem a guarda.

O inciso segundo aborda sobre o poder parental, no sentido de que o alienador possui a intenção de tonar difícil a autoridade do outro.

Em seguida, o inciso terceiro corresponde ao guardião que impossibilita a criança ou o adolescente de manter contato com o outro genitor, após a prolação de decisão concessiva da guarda compartilhada ou unilateral, de modo que impede que a criança tenha comunicação por meio de telefone celular, redes sociais ou outros comunicadores eletrônicos.

No que se refere ao inciso quarto, relaciona-se ao ato de o alienador dificultar as visitas com o genitor, quando apresenta influência sobre o menor de idade para realizar atividade mais interessantes do que receber a visita do alienado, ou seja, dificulta a convivência familiar entre ambos (MADALENO; MADALENO, 2015, p. 90).

Em consonância com o exposto, Carvalho (2018, p. 529) menciona que o inciso terceiro discorre acerca da impossibilidade de o menor de idade manter contato com o genitor alienado, por meio eletrôni- 
co, ligações ou até mesmo fora dos horários de visita. Não obstante, o inciso quarto apresenta que o alienador "[...] cria inúmeras situações agradáveis e interessantes para atrair o filho coincidentemente nos dias de visita, levando-o a recusar a convivência com o outro genitor [...]" (CARVALHO, 2018, p. 529).

Outrossim, o inciso quinto prevê uma forma de alienação em que o alienador omite informações pessoais de extrema importância sobre o filho, que dificulta a presença do genitor alienado na formação psicossocial da criança. Além disso, o inciso sexto trata de um ato altamente grave, que é o ato de alienação parental por meio de falsas denúncias contra o não guardião e seus familiares. E, ainda, o inciso sétimo aborda sobre a mudança de domicílio, sem justificativa para evitar a convivência da criança com o alienado (MOREIRA, 2015, p. 64).

Nessa esteira, Ramos (2016, p. 154) evidencia a respeito do inciso quarto, que trata do ato do alienador não cumprir o acordo judicial acerca da convivência ou visita do menor de idade com o genitor alienado, no sentido de dificultar o encontro entre ambos. $\mathrm{O}$ inciso quinto versa sobre a omissão de informações do menor (sic) para aquele que não está com a guarda, ao passo que o sexto corresponde ao ato mais grave de alienação parental, que diz respeito a falsas denúncias quanto ao alienado e seus familiares. Importante destacar que Moreira $(2015$, p. 64) e Ramos (2016, p.154) evidenciam as falsas denúncias como o ato mais grave de alienação parental.

Como pontua Gonçalves (2019, p. 297), a “[..] lei em apreço deixou claro o que caracteriza a alienação parental, transcrevendo uma série de condutas que se enquadram na referida síndrome, sem, todavia, considerar taxativo o rol apresentado". Nesse contexto, é oportuno destacar que a "[...] lista apresentada pelo legislador é apenas exemplificativa, ou seja, mesmo que a conduta no caso concreto não esteja descrita expressamente no citado dispositivo legal, ela pode caracterizar alienação parental [...]". (ARAUJO JÚNIOR, 2019).

De acordo com Trindade (2013, p. 25), além dos atos praticado nos moldes da Lei $n^{0} 12.318 / 10$, verifica-se que o alienador também possui condutas de desrespeito às regras da sociedade, é manipulador, apre- 
senta resistência em ser avaliado, possui falso interesse pelo processo judicial que tem por objetivo descobrir a alienação parental, além de ter por hábito atacar as decisões judiciais. Destaca-se que o rol apresentado pelo legislador tem apenas o objetivo de auxiliar na caracterização de condutas no âmbito do Poder Judiciário, sendo exemplificativo.

Não obstante, os atos do alienador para desqualificar a pessoa que não detém a guarda também consistem na "contaminação do objeto", uma vez que o guardião passa a destruir os objetos dados pelo alienado na tentativa de mantê-lo afastado. Além do mais, as hipóteses previstas no art. $2^{\circ}$ da Lei $n^{\circ} 12.318 / 10$ não são taxativas, consoante já mencionado, de maneira que o juízo de família poderá identificar outras atitudes caracterizadoras da alienação parental (ROSA, 2018, p. 458).

Nesse sentido, o art. $5^{\circ}$ da Lei $n^{\circ} 12.318 / 10$ dispõe que, "havendo indício da prática de alienação parental, em ação autônoma ou incidental, o juiz, se necessário, determinará perícia psicológica ou biopsicossocial”. Assim, o papel do psicólogo é detectar a alienação parental, realizar o acompanhamento, passar orientações para a família e, também, verificar possíveis alegações inverídicas durante o processo, como, por exemplo, a falsa denúncia de abuso sexual (PÁDUA, 2014, p. 101).

A realização da perícia é necessária para uma análise prudente e segura da situação concreta, por meio do apoio de um profissional que, com sua experiência e seu conhecimento técnico, fornecerá informações ao magistrado, colaborando com a formação de sua convicção (GIMENEZ, 2017, p. 48).

Ademais, o alienador pode apresentar impulsividade, baixa autoestima, medo do abandono, esperando que os menores (sic) estejam dispostos a obedecer aos seus comandos ou satisfazer seus anseios. Outrossim, pode até se desinteressar pela criança e fazer da demanda pela guarda apenas um instrumento de poder e controle, e não um desejo de afeto e cuidado (FREITAS, 2015).

Para Serafim e Saffi (2014, p. 99), “a motivação para a alienação pode ser muitas, como solidão decorrente da separação, falta de confiança, ódio direcionado ao ex-companheiro, motivações econômicas, vinganças". Consoante ficou demonstrado, algumas características e 
comportamentos do alienador são apontados em legislação específica, ou seja, a Lei n ${ }^{o} 12.318 / 10$, além do apoio da perícia psicológica para que, assim, possam ser tomadas as medidas necessárias em razão dos acontecimentos.

A seguir, será tratado a respeito da implantação de falsas memórias.

\subsection{Implantação de falsas memórias}

Orienta Féres-Carneiro (2007 apud MOLD, 2013, p. 119) que "a principal característica desse comportamento ilícito e doentio é a lavagem cerebral no menor (sic) para que atinja uma hostilidade em relação ao pai ou mãe visitante".

No dizer de Carvalho (2018, p. 525), a implantação de falsas memórias é uma das características do alienador, que faz com que o menor (sic) acredite que foi abandonado e rejeitado pela pessoa que não detém a guarda, contraindo ódio e sendo cúmplice do guardião. $O$ filho repete as mesmas frases que aprendeu durante o processo de alienação e, desse modo, afasta-se do genitor alienado.

Na opinião de Rizzardo (2019), a criança passa a refletir a respeito dos sentimentos negativos do guardião, uma vez que, dada a inocência própria da tenra idade, acredita nas histórias que lhe são contadas. Com o passar do tempo, o menor de idade apresenta consequências em face da implantação das falsas memórias, como a tendência a se reprimir ou esconder, cria problemas no círculo de amizades e na escola.

No mesmo sentido, Pereira menciona (2015, p. 74) sobre o alienador:

[...] é um usurpador da infância, que se utiliza da ingenuidade e inocência das crianças para aplicar o seu golpe, às vezes mais sutil, mais requintado, às vezes mais explícito e mais visível, e o filho acaba por apagar as memóriasde convivência e de boa vivência que teve com o genitor alienado.

Além do mais, a implantação de falsas memórias associa-se também com a denunciação caluniosa de abuso sexual, quando o alienador, na intenção de fazer com que o menor (sic) se afaste da pessoa que não detém a guarda, relata fatos que não ocorreram ou acrescenta detalhes 
irreais em situações que aconteceram. Desse modo, o filho passa a acreditar na história contada pelo guardião e afasta-se do outro genitor (ARAÚJO, 2013, p. 210).

Exemplificando o caso de implantação de falsas memórias, Guazzelli (2013, p. 192) apresenta o seguinte:

A criança narra ao guardião que o pai, durante uma visita, não deixou o filho tomar sorvete depois do parque. Em vez de a guardiã tentar explicar ao filho que já devia estar tarde e era quase hora do jantar, ou, ainda, que era um dia frio, ou, enfim, qualquer coisa que explicasse a conduta paterna, ela aproveita o ensejo e reforça para a criança que o papai é mau e que o menor tem de ter cuidado com ele, pois não é um bom pai.

Para Duarte (2013, p. 154), “as mentiras inventadas pelo guardião alienador têm como alvo principal denegrir e destruir o não guardião, dizendo que tal genitor (a) só quer ver os filhos para machucá-los, feri-los em sua integridade física, psicológica e moral". Partindo desse ponto, entende-se que as falsas memórias implantadas pelo alienador no menor de idade caracterizam a prática de alienação parental, sendo que o guardião, ao tentar afastar o cônjuge alienado, novamente causa prejuízo à criança.

Com essas considerações, a seguir será tratado a respeito da guarda e de suas modalidades.

\section{GUARDA E SUAS MODALIDADES}

De acordo com Cezar-Ferreira e Macedo (2016, p. 83), a guarda é um dos atributos do poder familiar, sendo que, "após a separação conjugal, qualquer que seja a organização de família, os filhos menores e os incapazes por razão que não a idade deverão ficar sob os cuidados diários de um dos pais ou de ambos".

E, na eventual dissolução do vínculo conjugal, os pais, como detentores da autoridade familiar, têm a prerrogativa de atuar na criação dos filhos menores, uma vez que assim podem conduzir a formação e educação destes. Dessa forma, poderá ser requerida a guarda ao juízo, com- 
partilhada ou consensual, observado o princípio do melhor interesse da criança, em atenção aos interesses morais, materiais, sociais e mentais do menor (sic) (GRISARD FILHO, 2016, p. 79; MADALENO, 2019).

Nesse sentido, leciona Figueiredo e Alexandridis (2014, p. 39): “[...] a guarda constitui um desdobramento do direito de convivência mantido em relação aos filhos [...] de zelar pelo cuidado, proteção, educação e custódia dos filhos, por um dos genitores ou por ambos de forma simultânea". Com essas considerações, passa-se aos tipos de guarda mais habituais, quais sejam, a compartilhada e a unilateral.

\subsection{Unilateral}

É oportuno verificar a guarda na modalidade unilateral. No entendimento de Pereira (2015, p. 359), é a guarda executada de forma unilateral por um dos genitores ou por uma única pessoa. Até o advento da Lei $\mathrm{n}^{\mathrm{o}} 11.698$, de 9 de junho de 2008, que trata da guarda compartilhada, era regra a unilateral. $O$ fato é que esta tem sido utilizada como um instrumento de poder entre os genitores que, pelo término conflituoso do relacionamento, utilizam os filhos como meio de vingança, sendo que essa característica pode ser observada como ato de alienação parental.

É relevante destacar que, caso não haja acordo entre os genitores, deverá ser observada a guarda compartilhada, desde que cumpridos os atributos do art. 227 da Constituição Federal da República Federativa do Brasil, levando em consideração o afeto e o princípio do melhor interesse da criança ou adolescente, de modo que, se um dos genitores não preencher o mínimo do que fora exposto, será atribuída a guarda ao outro (RODRIGUES, 2019, p. 294).

A dicção do dispositivo constitucional suso referido dispõe:

Art. 227. É dever da família, da sociedade e do Estado assegurar à criança, ao adolescente e ao jovem, com absoluta prioridade, o direito à vida, à saúde, à alimentação, à educação, ao lazer, à profissionalização, à cultura, à dignidade, ao respeito, à liberdade e à convivência familiar e comunitária, além de colocá-los a salvo de toda forma de negligência, discriminação, exploração, violência, crueldade e opressão. (BRASIL, 1988). 
$\mathrm{O}$ art. 1.583, $\S 1^{\circ}$, do Código Civil, na sua primeira parte, conceitua como guarda unilateral:

Art. 1.583. A guarda será unilateral ou compartilhada.

$\S 1^{\circ}$ Compreende-se por guarda unilateral a atribuída a um só dos genitores ou a alguém que o substitua (art. $1.584, \S 5^{\circ}$ ) e, por guarda compartilhada a responsabilização conjunta e o exercício de direitos e deveres do pai e da mãe que não vivam sob o mesmo teto, concernentes ao poder familiar dos filhos comuns.

$\S 5^{\circ}$ A guarda unilateral obriga o pai ou a mãe que não a detenha a supervisionar os interesses dos filhos, e, para possibilitar tal supervisão, qualquer dos genitores sempre será parte legítima para solicitar informações e/ou prestação de contas, objetivas ou subjetivas, em assuntos ou situações que direta ou indiretamente afetem a saúde física e psicológica e a educação de seus filhos. (BRASIL, 2002).

Na opinião de Gonçalves (2019, p. 523), “essa tem sido a forma mais comum: um dos cônjuges, ou alguém que o substitua, tem a guarda, enquanto o outro tem, a seu favor, a regulamentação de visitas”. O $\S 5^{\circ}$ do referido dispositivo legal prevê que: "Estabelece-se, assim, um dever genérico de cuidado material, atenção e afeto, por parte do genitor a quem não se atribuiu a guarda $[\ldots]$ ".

Consoante dispõe o art. 1.583 do Código Civil, o genitor que não obtiver a guarda do menor de idade tem o dever e o direito legal de supervisionar o interesse do menor (sic) e o desempenho do guardião, o que gera a responsabilidade de fiscalizar. Ademais, tem a prerrogativa de convivência, ou seja, o chamado "direito de visita". Não obstante, caso o menor estiver sobre os cuidados do outro cônjuge, em razão do direito de visitas, não haverá responsabilidade do guardião em relação à criança durante esse período (LEVY, 2016, p. 124; LISBOA, 2013, p. 177).

$\mathrm{O} \S 6^{\circ}$ do art. 1.584 do Código Civil aponta que o estabelecimento público ou privado é obrigado a prestar informações, a quaisquer dos genitores, sobre os filhos destes, sob pena de multa diária fixada em Lei, sendo esta mais uma forma de a pessoa que não detém a guarda supervisionar a atuação do guardião (ROSA, 2018, p.433). 
Esclarece Ramos (2016, p. 105) sobre a guarda unilateral que "a autoridade parental não é retirada do genitor não guardião, que continua podendo, ao lado do guardião, tomar decisões sobre o futuro do infante". E Lôbo (2008 apud MALUF; MALUF, 2018, p. 630) sustenta que "[...] nenhum fato é decisivo para determinar a escolha do melhor guardião, mas certamente viabiliza o melhor interesse do filho menor, a permanência com o genitor que melhor se adaptar à rotina da criança [...]".

Desse modo, a guarda unilateral é concedida a apenas um dos genitores, uma única pessoa, que será o guardião. O outro, ou seja, a pessoa que não possui a guarda, terá o dever e o direito de fiscalizar a atuação do guardião, embora possa também participar na vida pessoal do menor (sic), além de tomar decisões conjuntamente com o outro genitor. (PEREIRA, 2016, p. 57).

A seguir, será tratado a respeito da guarda compartilhada.

\subsection{Compartilhada}

Como mencionado por Filho (2002, p. 128 apud CEZAR-FERREIRA; MACEDO, 2016, p. 174), “a guarda compartilhada só se confere quando os pais manifestam opção por ela, através de acordo para melhor atender os interesses seus e dos filhos. Se o acordo não é possível, o Tribunal decide por eles". Assim, pode-se conceituar a guarda compartilhada como a possibilidade de os filhos de pais separados estarem sob os cuidados de ambos, de maneira que estes últimos possuem a mesma autoridade legal para conviver com os filhos em igualdade de condições e, também, tomar decisões para a sua vida (RAMOS, 2016, p. 73).

A conceituação de guarda compartilhada pode ser encontrada no art. 1.583 do Código Civil:

Art. 1.583. A guarda será unilateral ou compartilhada.

$\S 1^{\circ}$ Compreende-se por guarda unilateral a atribuída a um só dos genitores ou a alguém que o substitua $\left(\operatorname{art} .1 .584, \S 5^{\circ}\right.$ ) e, por guarda compartilhada a responsabilização conjunta e o exercício de direitos e deveres do pai e da mãe que não vivam sob o mesmo teto, concernentes ao poder familiar dos filhos comuns. 
$\S 3^{\circ} \mathrm{Na}$ guarda compartilhada, a cidade considerada base de moradia dos filhos será aquela que melhor atender aos interesses dos filhos. (BRASIL, 2002).

A razão pela qual se estabelece a guarda compartilha é no sentido de ambos os pais exercerem suas funções e ajudarem a manter o laço familiar, ainda que haja a separação dos genitores, ao contrário da guarda unilateral, que pode afastar a presença e a participação do genitor que não ficou com a guarda (MADALENO; MADALENO, 2018, p. 201). Além disso, esclarece Akel (2016, p. 43) que "na guarda compartilhada deve inexistir disputa entre os genitores que, de forma equilibrada, deverão viver em sua plenitude a relação com seus filhos".

Ademais, o $\S 2^{\circ}$ do art. 1.584 do Código Civil estabelece que, quando não houver acordo entre os genitores sobre a guarda, será aplicada a guarda compartilhada, salvo na hipótese de um dos genitores declarar que não deseja a guarda. Fica caracterizado que, com essa redação, o referido dispositivo legal denota que a guarda compartilhada torna-se preponderante, de forma que prevalece sobre a unilateral (PEGHINI, 2016, p. 59). Partindo desse pressuposto, Levy (2016, p. 124) aborda que "[...] a lei é projetada com o objetivo de enaltecer e garantir formalmente a participação igualitária da figura paterna na criação e educação de seus filhos, buscando gerar uma nova cultura e transformar o paradigma vigente $[\ldots]$ "..

Além disso, a Lei sobre guarda compartilhada, alterada no ano de 2008 e, em seguida, no ano de 2014, teve como objetivo assegurar o afeto entre o menor e o pai ou a mãe após a separação do casal, uma vez que apenas um deles ficaria com a guarda. Como consequência, a guarda compartilhada foi adotada com prioridade sobre as demais (GROENINGA, 2016, p. 145).

Diante disso, ainda que não haja acordo, leciona Gama (2016, p. 164) que "outro aspecto de relevo foi o reconhecimento da possibilidade de a guarda compartilhada ser estabelecida mesmo na falta de acordo entre os pais, tendo como norte e referência o melhor interesse da criança [...]". Nesse mesmo norte, Lima (2016, p. 309) aponta que, "ao se avaliar a adoção de qualquer modalidade de guarda de filhos, é imperioso 
que sempre se tenha como regra norteadora o princípio do melhor interesse da criança e adolescente [...]".

Ressalta-se que a guarda compartilhada não possui como definição que o filho resida metade do tempo com o pai e metade com a mãe; diz respeito ao genitor não guardião participar dos eventos, da educação, de decisões importantes na vida do menor tanto quanto o outro genitor, o que traz mais equilíbrio na função materna e paterna (WEISS, 2016, p. 330). Observa-se que a guarda compartilhada é uma maneira de distribuir as funções dos pais e, também, fazer com que se minimize eventual sofrimento oriundo da separação dos genitores.

A seguir, será tratado a respeito da denunciação caluniosa e da alienação parental.

\section{DENUNCIAÇÃO CALUNIOSA E ALIENAÇÃO PARENTAL}

A denunciação caluniosa é temática relevante no âmbito da alienação parental, na medida em que vislumbrada em muitas situações no Poder Judiciário. É conceituada no sentido de que o alienador que, na intenção de romper a relação entre a pessoa que não detém a guarda e a criança ou adolescente, utiliza o Poder Judiciário para promover campanha desmoralizante, por meio de falsas denúncias, inclusive em relação a abuso sexual. Salienta-se que essa conduta do alienador tem por objetivo convencer o juiz e os profissionais do caso, mas o principal foco é convencer o próprio filho de que o fato realmente existiu, por meio da implantação de falsas memórias (SILVA, 2015, p. 38).

Na visão de Silva (2015, p. 38), “[...] esse mecanismo de falsas acusações e inverdades disseminadas é na maioria das vezes usado exclusivamente para ofuscar os operadores do direito [...] principalmente aquele que possui a prerrogativa de julgar e decidir sobre o ato espúrio”. Os relatos de abuso sexual são utilizados como subterfúgio para que o alienador ganhe mais tempo com o menor e faça com que o genitor alienado passe a ser considerado como uma pessoa mal-intencionada.

No dizer de Rosa (2018, p. 457), o alienador busca qualquer meio para afastar o não guardião da criança. A partir disso, é realizada a im- 
plantação de falsas memórias, em que o guardião, mesmo expondo o menor de idade a exames e perícia, continua com o jogo de manipulação para suspender a convivência do alienado com o filho. Ademais, o requerimento de medida protetiva, segundo a Lei Maria da Penha, desprovido de fundamento, também se apresenta como meio de afastar a criança e o genitor.

De modo geral, segundo Carvalho (2018, p. 530), as denúncias falsas podem ocorrer " [...] após o alienador implantar na memória do filho informações irreais e ilusória, induzindo-o a acreditar e relatar fatos inverídicos como se efetivamente tenham ocorrido, o que é denominado de síndrome das falsas memórias".

Um dos argumentos mais utilizados e eficazes para afastar o não guardião da criança é o relato de abuso sexual, consoante já mencionado, uma vez que, comprovado, causa a ruptura definitiva do contato entre ambos. Por diversas vezes, esse relato é caracterizado como uma falsa denúncia, apenas com o propósito de alcançar, perante o Poder Judiciário, a ruptura da convivência do não guardião com o filho. $\mathrm{O}$ genitor alienado passa a ser um intruso ou inimigo, sendo desmoralizado. Dessa maneira, o guardião obtém o controle da guarda sobre o menor (sic) (DUARTE, 2013, p. 146).

Como descrito por Ramos (2016, p. 155), essa denúncia, levada ao juízo competente, desencadeia situações delicadas. Durante o período em que se determina a realização de perícia para averiguar a veracidade dos fatos, é recomendável que o juiz reverta a guarda ou suspenda as visitas, de modo que a convivência entre ambos, nessa etapa, poderá ficar prejudicada. Assim, como é de difícil identificação a existência dos abusos, a criança poderá sofrer consequências irreversíveis, tais como, paranoias, em razão da implantação de falsas memórias, além da perda de confiança, isolamento, estresse, desvio de personalidade e depressão.

Segundo Guazzelli (2013, p. 195):

A falsa denúncia é, também, uma forma de abuso, pois as crianças são, compulsoriamente, submetidas a uma mentira, sendo emocional e psicologicamente manipuladas e abusadas. Essa falsa denúncia passa a fazer parte de suas vidas e, por causa disso, terão de en- 
frentar vários procedimentos (análise social, psiquiátrica e judicial) com o fito de esclarecimento da verdade.

No entendimento de Araújo (2013, p. 209), o alienador utiliza-se do Poder Judiciário na sua vingança, ao passo que, enquanto o processo está em andamento, tem a oportunidade de implantar ainda mais falsas memórias sobre o alegado abuso e o abandono por parte do genitor alienado. A criança fica no lugar da verdadeira vítima no processo, dessa vez não sexual, e sim moral e emocional.

$\mathrm{Na}$ avaliação de crianças vítimas de falsas acusações de abuso sexual, visualiza-se as consequências dessa prática de alienação parental, em que os menores (sic) apresentam depressão infantil, ansiedade, transtorno de identidade, dupla personalidade, sentimento de culpa e insegurança. Ao longo do tempo, a criança passa a acreditar que realmente foi abusada e sentirá as consequências nos futuros relacionamentos (CALÇADA, 2015, p. 75). Nesse tipo de prática de alienação parental, o maior atingido não é o alienado, mas sim a criança.

Apesar de ser verificada por prova técnica na modalidade de perícia, alguns indícios são relevantes para visualizar que a denúncia de abuso sexual é falsa. É possível destacar que a criança precisa de estímulo para lembrar o que realmente aconteceu, quando há contradição no relato. Além disso, o sentimento de vergonha ou culpa são escassos, o menor não apresenta atraso educativo em consequência do suposto abuso e, também, não possui agressividade ou baixa autoestima (ESTROUGO, 2010, p. 535; SILVA, 2013, p. 351).

A seguir, será apresentada a conclusão, em observância à fundamentação teórica mencionada no artigo.

\section{CONCLUSÃO}

Conforme apurado, este artigo tratou sobre a alienação parental, seu conceito, as características e as principais condutas praticadas pelo alienador, além de expor certas consequências causadas ao menor de idade. Em outro norte abordou acerca da guarda e suas modalidades mais usuais, ou seja, a unilateral e a compartilhada. 
Frisa-se, outrossim, que a alienação parental faz parte do âmbito jurídico do Direito de Família e envolve o indivíduo que detém a guarda da criança, a própria criança e a pessoa que não possui a guarda. Destaca-se também que o principal prejudicado na prática da alienação parental não é o guardião ou a pessoa que não possui a guarda, mas sim a criança envolvida.

Assim, conclui-se que a alienação parental viola as prerrogativas das crianças e dos adolescentes, causa traumas e, em consequência, exige uma rápida solução por meio do Poder Judiciário.

\section{REFERÊNCIAS}

APOSTOLO, Helena Maria Ribeiro. Guarda compartilhada pode prevenir a alienação parental? In: SOUSA, Maria Quitéria Lustosa de (org.). Alienação parental e família contemporânea, volume 2: um estudo psicossocial. Recife: FBV, 2015.

ARAUJO JÚNIOR, Gediel Claudino de. Prática no direito de família. 11. ed. São Paulo: Atlas, 2019. E-book. Acesso restrito via Minha Biblioteca.

ARAÚJO, Sandra Maria Baccara. O genitor alienador e as falsas acusações de abuso sexual. In: DIAS, Maria Berenice (org.). Incesto e alienação parental: de acordo com a Lei 12.318/2010. São Paulo: Thomson Reuters Revista dos Tribunais, 2013.

BRASIL. [Constituição Federal (1988)]. Constituição da República Federativa do Brasil. Brasília, DF: Presidência da República, 1988. Disponível em: http://www.planalto.gov.br/ccivil_03/Constituicao/ Constituicao.htm. Acesso em: 07 jan. 2021.

BRASIL. Lei no 12.318, de 26 de agosto de 2010. Dispõe sobre a alienação parental e altera o art. 236 da Lei no 8.069, de 13 de julho de 1990. Brasília, DF: Presidência da República, 2010. Disponível em: http://www.planalto.gov.br/ccivil_03/_ato2007-2010/2010/lei/112318. htm. Acesso em: 13 março 2021. 
BRASIL. Lei $\mathbf{n}^{\mathbf{0}} \mathbf{1 3 . 0 5 8}$, de 22 de dezembro de 2014. Altera os arts. $1.583,1.584,1.585$ e 1.634 da Lei $n^{\circ} 10.406$, de 10 de janeiro de 2002 (Código Civil), para estabelecer o significado da expressão "guarda compartilhada" e dispõe sobre sua aplicação. Brasília, DF: Presidência da República, 2014. Disponível em: http://www.planalto.gov.br/ ccivil_03/_ato2011-2014/2014/lei/113058.htm. Acesso em: 12 março 2021.

CALÇADA, Andreia. Falsas acusações de abuso sexual - Um olhar psicológico para avaliar e intervir. In: SOUSA, Maria Quitéria Lustosa de (org.). Alienação parental e família contemporânea, volume 2: um estudo psicossocial. Recife: FBV, 2015.

CARVALHO, Dimas Messias de. Direito das famílias. 6. ed. São Paulo: Saraiva, 2018.

CARVALHO, Dimas Messias de. Direito das famílias. 7. ed. São Paulo: Saraiva Educação, 2019.

CEZAR-FERREIRA, Verônica A. da Motta; MACEDO, Rosa Maria Stefanini de. Guarda compartilhada: uma visão psicojurídica. Porto Alegre: Artmed, 2016.

DIAS, Maria Berenice. Alienação parental e perda do poder familiar. [Porto Alegre], 2010. Disponível em: https://bit.ly/33Ju5JP. Acesso em: 04 fev. 2021

DUARTE, Lenita Pacheco Lemos. Qual a posição da criança envolvida em denúncias de abuso sexual quando o litígio familiar culmina em situações de alienação parental: inocente, vítima ou sedutora?. In: DIAS, Maria Berenice (org.). Incesto e alienação parental: de acordo com a Lei 12.318/2010. São Paulo: Thomson Reuters Revista dos Tribunais, 2013.

ESTROUGO, Mônica Guazzelli. A falsa denúncia de abuso sexual. In: ZIMENMAN, David; COLTRO, Antônio Carlos Mathias (org.). Aspectos psicológicos na prática jurídica: obra coletiva. São Paulo: Millennium Editora, 2010. 
FIGUEIREDO, Fábio Vieira; ALEXANDRIDIS, Georgios. Alienação parental. 2. ed. São Paulo: Saraiva, 2014. E-book. Acesso restrito via Minha Biblioteca.

FREITAS, Douglas Phillips. Comentários à lei 12.318/2010.4. ed. Rio de Janeiro: Forense, 2015. E-book. Acesso restrito via Minha Biblioteca.

GAMA, Guilherme Calmon Nogueira da. Guarda compartilhada: novo regime da guarda de criança e adolescente à luz das leis $n^{0} 11.698 / 2008$ e $n^{\circ} 13.058 / 2014$. In: COLTRO, Antônio Carlos Mathias; DELGADO, Mário Luiz (org.). Guarda compartilhada. São Paulo: Método; Rio de Janeiro: Forense, 2016.

GIMENEZ, Angela. Alienação parental: sete anos de lei. Rev. IBDFAM: Família e Sucessões, Belo Horizonte, v. 21. 2017.

GONÇALVES, Carlos Roberto. Direito civil brasileiro, volume 6: direito de família. 16. ed. São Paulo: Saraiva, 2019. E-book. Acesso restrito via Minha Biblioteca.

GONÇALVES, Carlos Roberto. Direito civil brasileiro, volume 6: direito de família. 16. ed. São Paulo: Saraiva, 2019. E-book. Acesso restrito via Minha Biblioteca.

GRISARD FILHO, Waldyr. Guarda compartilhada: um novo modelo de responsabilidade parental. 8. ed. São Paulo: Revista dos Tribunais, 2016.

GROENINGA, Giselle Câmara. Guarda compartilhada - A efetividade do poder familiar. In: COLTRO, Antônio Carlos Mathias; DELGADO, Mário Luiz (org.). Guarda compartilhada. São Paulo: Método; Rio de Janeiro: Forense, 2016.

GUAZELLI, Mônica. A falsa denúncia de abuso sexual. In: DIAS, Maria Berenice (org.). Incesto e alienação parental: de acordo com a Lei 12.318/2010. São Paulo: Thomson Reuters Revista dos Tribunais, 2013. 
LEVY, Fernanda Rocha Lourenço. Guarda compartilhada: a mediação como instrumento para a construção de um acordo parental sustentável. In: COLTRO, Antônio Carlos Mathias; DELGADO, Mário Luiz (org.). Guarda compartilhada. São Paulo: Método; Rio de Janeiro: Forense, 2016.

LIMA, Suzana Borges Viegas de. A nova realidade. In: COLTRO, Antônio Carlos Mathias; DELGADO, Mário Luiz (org.). Guarda compartilhada. São Paulo: Método; Rio de Janeiro: Forense, 2016.

LISBOA, Roberto Senise. Manual de direito civil, volume 5: direito de família e sucessões. 8. ed. São Paulo: Saraiva, 2013. E-book. Acesso restrito via Minha Biblioteca.

LÔBO, Paulo. Direito civil: famílias. 7. ed. São Paulo: Saraiva, 2017.

MADALENO, Ana Carolina Carpes; MADALENO, Rolf. Síndrome da alienação parental: importância da detecção. 6. ed. Rio de Janeiro: Forense, 2019.

MADALENO, Ana Carolina Carpes; MADALENO, Rolf. Síndrome da alienação parental: importância da detecção. 3. ed. Rio de Janeiro: Forense, 2015.

MALUF, Carlos Alberto Dabus; MALUF, Adriana Caldas do Rego Freitas Dabus. Curso de direito de família. 3. ed. São Paulo: Saraiva, 2018.

MOLD, Cristian Fetter. Alienação Parental recíproca. In: DIAS, Maria Berenice (org.). Incesto e alienação parental: de acordo com a Lei 12.318/2010. São Paulo: Thomson Reuters Revista dos Tribunais, 2013.

MOREIRA, Luciana Maria Reis. Alienação parental. Belo Horizonte: D’plácido, 2015.

OLIVEIRA, Ana Lúcia Navarro de. A alienação parental e suas implicações no contexto familiar. In: SOUSA, Maria Quitéria Lustosa de (org.). Alienação parental e família contemporânea, volume 2: um estudo psicossocial. Recife: FBV, 2015. 
PEGHINI, Cesar Calo. Poder familiar e guarda: um caminho assertivo para a devida aplicação da guarda compartilhada. In: COLTRO, Antônio Carlos Mathias; DELGADO, Mário Luiz (org.). Guarda compartilhada. São Paulo: Método; Rio de Janeiro: Forense, 2016.

PEREIRA, Caio Mário da Silva. Instituições de direito civil, volume 5: direito de família. 27. ed. Rio de Janeiro: Forense, 2019. E-book. Acesso restrito via Minha Biblioteca.

PEREIRA, Rodrigo da Cunha. Alienação parental: uma inversão da relação sujeito e objeto. In: DIAS, Maria Berenice (org.). Incesto e alienação parental: de acordo com a Lei 12.318/2010. São Paulo: Thomson Reuters Revista dos Tribunais, 2013.

PEREIRA, Rodrigo da Cunha. Dicionário de direito de família e sucessões. São Paulo: Saraiva, 2015. E-book. Acesso restrito via Minha Biblioteca.

PEREZ, Elizio Luiz. Breves comentários acerca da Lei da alienação parental. (Lei 12.318/2010). In: DIAS, Maria Berenice (org.). Incesto e alienação parental: de acordo com a Lei 12.318/2010. São Paulo: Thomson Reuters Revista dos Tribunais, 2013.

RAMOS, Patricia Pimentel de Oliveira Chambers. Poder familiar e guarda compartilhada: novos paradigmas do direito de família. 2. ed. São Paulo: Saraiva, 2016.

RIZZARDO, Arnaldo. Direito de família. 10. ed. Rio de Janeiro: Forense, 2019. E-book. Acesso restrito via Minha Biblioteca.

ROCHA, Sandra Mônica de Siqueira. A alienação parental e o abuso de direito nas relações de família. In: SOUSA, Maria Quitéria Lustosa de (org.). Alienação parental e família contemporânea, volume 2: um estudo psicossocial. Recife: FBV, 2015.

ROSA, Conrado Paulino da. Curso de direito de família contemporâneo. 4. ed. Salvador: Juspodivm, 2018. 
SERAFIM, Antonio de Pádua; SAFFI, Fabiana. Psicologia e práticas forenses. 2. ed. São Paulo: Manole, 2014.

SILVA, Carmésia Virginia Mesquita e. Ofensa sexual e pseudo-ofensa sexual: a falsa denúncia estratégia utilizada por pais alienadores nas famílias em processo de separação e divórcio. In: SOUSA, Maria Quitéria Lustosa de (org.). Alienação parental e família contemporânea, volume 2: um estudo psicossocial. Recife: FBV, 2015.

TRINDADE, Jorge. Síndrome da alienação parental (SAP). In: DIAS, Maria Berenice (org.). Incesto e alienação parental: de acordo com a Lei 12.318/2010. São Paulo: Thomson Reuters Revista dos Tribunais, 2013.

ULLMANN, Alexandra. A alienação parental além da família. In: SOUSA, Maria Quitéria Lustosa de (org.). Alienação parental e família contemporânea, volume 2: um estudo psicossocial. Recife: FBV, 2015.

WAQUIM, Bruna Barbieri. Alienação familiar induzida: aprofundando o estudo da alienação parental. 2. ed. Rio de Janeiro: Lumen Juris, 2018.

WEISS, Telma Kutnikas. A Lei da guarda compartilhada: uma breve visão psicanalítica. In: COLTRO, Antônio Carlos Mathias; DELGADO, Mário Luiz (org.). Guarda compartilhada. São Paulo: Método; Rio de Janeiro: Forense, 2016.

Recebido em: 25/03/2021

Aprovado em:10/08/2021 